\title{
Age- and Sex- Related Changes in Pineal Gland: A Morphological and Histological Study
}

\author{
K G Arunkumar, A Amar Jayanthi, C K Indira, V K Girijamony \\ Department of Anatomy, Government Medical College, Thrissur, India
}

Email address:

drkg_arunkumar@yahoo.com (K G Arunkumar)

To cite this article:

K G Arunkumar, A Amar Jayanthi, C K Indira, V K Girijamony. Age- and Sex- Related Changes in Pineal Gland: A Morphological and Histological Study. American Journal of Internal Medicine. Special Issue: Toxicology. Vol. 3, No. 6-1, 2015, pp. 10-13.

doi: 10.11648/j.ajim.s.2015030601.13

\begin{abstract}
Introduction: Pineal gland is believed to be an endocrine gland, melatonin being the principal hormone secreted by it. Updating any knowledge about the anatomy of pineal gland will expand our understanding of pineal physiology and pathophysiology and of the possible medical use of pineal compounds. Materials and Methods: We conducted a cross-sectional observatory study in pineal gland specimens collected from human subjects during autopsy after obtaining written informed consent from relatives. Subjects died of malignancy or head injury were excluded from the study. Morphological and histological analysis was done after preservation. Results: There were 90 adult specimens and 12 fetal specimens. Mean ( \pm SD) age, length of specimen, width, thickness (centimeters) and weight (grams) of specimen were 41.37 $\pm 23.3,0.79 \pm 0.17,0.59 \pm 0.13,0.35 \pm$ 0.10 and $0.08 \pm 0.04$ respectively. The average number of pinealocytes and glial cells per field were $184.6 \pm 29.41$ and $7.20 \pm$ 2.65 respectively. Incomplete lobules were seen in 52 adult specimens and complete in 38. Calcification was observed in 69 specimens. Changes of pattern of lobule from incomplete to complete and increase in calcification were found to be significantly correlated with advancing age. Conclusion: Increasing calcification and change in lobular pattern are observed as advancing age related changes in present study. Estimation of melatonin and data regarding factors affecting these changes may be done further to identify its pathophysiological significance.
\end{abstract}

Keywords: Pinealocyte, lobulation of pineal gland, calcification of pineal gland

\section{Introduction}

Herophilos was the first to discover the human pineal gland $^{1}$. The pineal gland, the seat of the soul, also called the pineal body, epiphysis cerebri, or third eye, is a small pine cone shaped organ situated on the dorsum of the midbrain, above and between the superior colliculi ${ }^{2}$. The pineal gland is covered with piamater. The gland is divided into lobules by fibrous septa from the piamater - a process which takes place mostly during childhood. Pinealocytes and astrocytes are the principal cells in the pineal gland ${ }^{3}$. It is believed to be an endocrine gland, melatonin being the principal hormone secreted by it. Melatonin acts as an endocrine transducer, inducing rhythmical changes in the endocrine activity of the hypothalamus, pituitary, ovaries and testis in response to changes in light received by the retina ${ }^{3}$.

Microscopically the pineal gland shows changes with advancing age. Various internal and external exposures may be responsible for age related changes. In infants it is large and cells are arranged in alveoli. Signs of involution are seen even before puberty. Calcification of the pineal gland results in the formation of corpora arenacea (also known as brain sand or acervuli $)^{4}$. Corpora arenacea appear in tissue which gradually increase in number and size with age and impart radiological shadow; a displaced calcified pineal indicates a space occupying lesion above the tentorium ${ }^{5}$. Much discussion is now going around endocrine functions of pineal gland. Literature suggests presence of melatonin and its precursor serotonin in pinealocytes. The discovery of melatonin in 1958 awakened interest in the link between pineal gland and mental disorders thereby challenging the concept of vestigial role of pineal gland ${ }^{6}$.

Currently melatonin is used pharmacologically to prevent jet lag and to induce sleep. Postulated effects of melatonin in man include an influence in the onset of puberty and body biorhythms. It has been studied for a number of other functions including contraception, protection against endogenous oxidants, prevention of aging, treatment of depression, HIV infection and a variety of cancers ${ }^{7}$. 
Recent studies have shown the presence of melanin pigments in the pineal gland contrary to what has been given in standard text books ${ }^{8}$. Scientists are often confronted with the negative, equivocal, or contradictory data obtained from research on this enigmatic organ. Updating any knowledge about the anatomy of pineal gland will expand our understanding of pineal physiology and pathophysiology and of the possible medical use of pineal compounds.

This work was done to find out morphological and histological features in human pineal gland as age advances. Also an attempt was made to find out any sex- differences in terms of gross and microscopic structure of pineal gland.

\section{Materials and Methods}

We conducted a cross-sectional observatory study after obtaining institutional research committee and ethical committee clearance certificates from Government Medical College, Thrissur. Pineal gland specimens were collected from human subjects during autopsy after obtaining written informed consent from relatives. Subjects died of malignancy or head injury were excluded from the study. Pineal glands were removed from the brain during autopsy along with the stalk. Ninety specimens were collected in this manner. Parameters recorded prior to fixation were shape, colour, and location of pineal gland. The specimens were put in Bouin's fluid (saturated aqueous solution of picric acid, formalin, and glacial acetic acid) ${ }^{9}$ for fixation immediately after collection. After 48 hours of fixation, the following parameters were recorded for autopsy specimens - length, width, thickness, and weight. Length, width, and thickness were measured in centimeters using calipers. Weight was measured in grams using digital weighing machine. Significant photographs were taken. Specimens were then processed for light microscopy. Steps of tissue processing done prior to staining included dehydration in graded concentration of alcohol, clearing in xylene, and embedding in paraffin. Paraffin tissue blocks were prepared using Leukhart's L pieces. Four micrometre sections were prepared from tissue blocks using rotary microtome ${ }^{10,11}$. Sections were transferred to hot water bath and then mounted on glass slides using albumin as adhesive. Mounted sections were then stained. Stains used were Haematoxylin \& Eosin?, Masson-Fontana for melanin pigments ${ }^{9,11,12}$, Mallory's phosphotungstic acid haematoxylin (PTAH) for neuroglial cells and nerve fibres ${ }^{9,12}$, and Von Kossa silver test for calcification $^{9,11,12}$. The histological analysis was performed using the optical microscope BX51 Olympus ${ }^{\circledR}$, coupled to the reading equipment, with mobile and fixed imaging, using Windows and software Magnus in order. During light microscopy the following features were assessed: pattern of lobules, number of pinealocytes and neuroglial cells, calcification, melanin pigments if any. From each slide, three fields were analyzed at 40x magnification. Patterns of lobular arrangement were studied. Lobules with poorly defined septa were categorized as incomplete and those with well defined septa as complete. The distinction between the two types of cells was made according to staining characteristics of their nuclei. The pinealocytes nuclei were euchromatic and irregular and larger than glial cell nuclei and cytoplasm pale stained. The glial cell nuclei were elongated and smaller and darker stained than pinealocytes nuclei. The glial cells were less in number than pinealocytes. They were more concentrated around the septa and blood vessels.

The glial cells were more clearly distinguished using phosphotungstic acid hematoxylin (PTAH) staining.

All specimens were microscopically examined for the presence or absence of calcification. Two types of calcification were noted: intrapineal and extrapineal. Calcification present within the parenchyma of the gland was intrapineal and that within the capsule of the gland extrapineal. Von Kossa silver test for calcification was done to demonstrate calcification more clearly.

The number of pinealocytes and glial cells were calculated by taking the average of the values obtained from three fields of each slide. All specimens were microscopically examined for the presence or absence of calcification.

Fetal specimens were collected from fetuses stored in the department of Anatomy and from the Department of Obstetrics and Gynecology after obtaining ethical committee clearance. The fetuses were embalmed with $10 \%$ formalin by hypodermic method. The brain was fixed using $10 \%$ formalin by infusion through anterior fontanelle and posterior fontanelle. After six weeks of fixation, the skull cavity was opened and the pineal glands were collected. Since the fetuses were obtained only after some delay following their death, the pineal gland specimens could be collected successfully from twelve fetuses only. The fetal pineal specimens thus collected were studied microscopically in the above manner as in the adult pineal specimens.

Data collected from pineal specimens were entered in Microsoft Excel work sheet. Statistical analysis was done using SPSS software. The continuous variables were expressed in mean with standard deviation. The qualitative variables were expressed in frequency and proportions. Correlation of various factors was done using multivariate regression technique. $\mathrm{p}$ value of $<0.05$ was considered as statistically significant. Since data collected from fetal specimens were incomplete, those data were not subjected to statistical analysis.

\section{Results}

We analysed a total of 102 specimens of which ninety were adult specimens and 12 were fetal specimen.

\subsection{Morphological Parameters}

Length, width, thickness, and weight- were studied in ninety adult pineal specimens and is shown in table 1

Table 1. Mean value of morphological parameters of pineal gland.

\begin{tabular}{llll}
\hline Variable & \multicolumn{3}{l}{ Mean \pm Standard deviation } \\
\hline & Male & Female & Total \\
\hline Age in years & $42.03 \pm 23.32$ & $40.5 \pm 23.54$ & $41.37 \pm 23.3$ \\
Length in centimeter & $0.79 \pm 0.17$ & $0.79 \pm 0.16$ & $0.79 \pm 0.17$ \\
\hline
\end{tabular}




\begin{tabular}{llll}
\hline Variable & \multicolumn{4}{l}{ Mean \pm Standard deviation } & \\
\hline & Male & Female & Total \\
\hline Width in centimeter & $0.60 \pm 0.14$ & $0.58 \pm 0.13$ & $0.59 \pm 0.13$ \\
Thickness in centimeter & $0.35 \pm 0.10$ & $0.35 \pm 0.10$ & $0.35 \pm 0.10$ \\
Weight in gram & $0.08 \pm 0.04$ & $0.08 \pm 0.04$ & $0 . .08 \pm 0.04$ \\
\hline
\end{tabular}

When statistical test was done to find out correlation of age with morphological parameters, the width and weight of pineal gland were found to decrease with advancing age significantly (table 2). But when multivariate regression technique was carried out to find out influence of morphological parameters on age, none of the variables was found to be influencing age.

Table 2. Correlation of age with morphological parameters of pineal gland.

\begin{tabular}{llll}
\hline Variable & $\begin{array}{l}\text { Karl - Pearson's } \\
\text { correlation co efficient }\end{array}$ & p value & $\begin{array}{l}\text { p value(after } \\
\text { multivariate } \\
\text { regression) }\end{array}$ \\
\hline Length & -0.16 & 0.14 & 0.779 \\
Width & -0.3 & 0.004 & 0.116 \\
Thickness & -0.11 & 0.3 & 0.644 \\
Weight & -0.29 & 0.005 & 0.165 \\
\hline
\end{tabular}

There was no statistically significant difference between male and female with regard to morphological parameters studied.

\subsection{Light Microscopic Features}

Light microscopic analysis of pineal gland sections stained with routine hematoxylin and eosin showed two types of cells - pinealocytes and glial cells. The gland was found to be enclosed within a capsule derived from pia mater which sent septa inwards, thereby dividing the gland parenchyma into lobules.

The average number of pinealocytes per field was $184.6 \pm$ 29.41. The average number of glial cells per field was $7.20 \pm$ 2.65 .

The other microscopic parameters studied include pattern of lobule and presence or absence of calcification. Of the two patterns of lobular arrangement noted in this study $57.8 \%$ ( $\mathrm{n}=52,29$ males and 23 females) of adult pineal glands showed incomplete lobules.

All specimens were microscopically examined for the presence or absence of calcification. Calcification was observed in 69 specimens $(76.7 \%)$ - 39 males and 30 females.

The number of the two different types of cells did not show any statistically significant changes as age advanced. Lobules were found to have an independent statistically significant influence on age, with tendency to become complete as age advanced (table 3). Multivariate regression technique was done to find out influence of microscopic features on age. It showed statistically significant differences between ages, with tendency for the lobules to become complete as age advanced.

Calcification was seen in all age groups studied. The frequency of pineal calcification increased with age throughout life. The lowest age at which it was present was in a 4 year old boy. Two types were noted: intrapineal and extrapineal. As an independent parameter, calcification was found to have statistically significant differences between ages, with tendency for, as age advanced. Multivariate regression technique done showed statistically significant influence of calcification on age (table 3 ).

Table 3. Correlation of age with microscopic features under study in pineal gland.

\begin{tabular}{llll}
\hline Variable & Test statistic & p value & $\begin{array}{l}\text { p value after regression } \\
\text { analysis }\end{array}$ \\
\hline Pinealocytes & $\mathrm{r}=-0.17$ & 0.12 & 0.3 \\
Glial cells & $\mathrm{r}=0.05$ & 0.63 & 0.53 \\
Lobule & $\mathrm{t}=-2.94$ & 0.004 & 0.02 \\
Calcification & $\mathrm{t}=-2.74$ & 0.01 & 0.06 \\
\hline
\end{tabular}

No statistically significant differences were noted between the two sexes with regard to the number of pinealocytes and to the number of glial cells. The pattern of lobule as well as frequency of calcification did not show any statistically significant differences between the two sexes.

Morphological and histological studies in ninety adult pineal glands did not reveal any statistically significant age related or sex related changes except pattern of lobule and calcification.

In fetal pineal specimens, morphological study could not be done due to minute size of the gland. Light microscopic study did not reveal any lobular pattern of arrangement. All fetal specimens revealed presence of capsule around the glands. The differentiation of the two types of cells as seen in adult pineal gland could not be made out clearly in fetal specimens. So the quantitative analysis of the cells was not done. In none of the fetal specimens, calcification was found.

\section{Discussion}

This work was done to find out morphological and histological features in human pineal gland in Kerala population as age advanced. Also an attempt was made to find out any sex- differences in terms of gross and microscopic structure of pineal gland. Morphological and histological studies in ninety post natal pineal glands revealed statistically significant age related changes in pattern of lobule and calcification. As age advanced, pattern of lobule changed from incomplete to complete. The tendency for lobules to become complete is also explained by Cooper ${ }^{13}$.

Also, tendency for calcification increased with age. Svetlana Antic et $\mathrm{al}^{14}$ and Gusek et $\mathrm{al}^{15}$ in their studies have observed the same pattern of results regarding calcification.

This work failed to demonstrate presence of melanin pigment within pinealocytes contrary to data provided by some of the earlier studies, but in accordance with data given in standard text books. The presence of melanin pigments within pinealocytes as shown by Masson Fontana stain in some articles cannot be taken as confirmatory evidence of its presence because of large number of false positive reactions given by other possible compounds within the pineal gland.

In fetal pineal specimens, light microscopic study did not reveal any lobular pattern of arrangement. A definite capsule was seen in all the fetal specimens. In none of the fetal specimens, calcification was found. The parenchymal cells 
could not be differentiated.

Electron microscopic studies were not included in this work. Functional anatomical studies are never complete without investigations like immunohistochemical studies and serum levels of hormones.

The role of melatonin in aging and Alzheimer's disease suggested by $\mathrm{Wu} \mathrm{YH} \mathrm{et} \mathrm{al}{ }^{16}$, the association of amount of brain sand and schizophrenia shown by Savel'ev et $\mathrm{al}^{17}$, the importance of pineal gland anatomy in the surgical management of pineal tumors ${ }^{18}$, all these signify the importance of updating data on pineal gland anatomy. In order to correlate the morphological and microscopic features of pineal gland with its secretory activity and physiological significance, investigations in the form of serum estimation of melatonin and immunohistochemical studies of enzymes in the pinealocytes are needed which could not be included in this work.

There are many internal and external toxins implicated in the causation of diseases like Alzheimer's and schizophrenia which include environmental toxins, infectious agents, drugs etc. Since our work was done postmortem previous exposure history was not available in case records. It is advisable to study relation of exposure to various agents and changes seen in pineal gland which may throw light to pathophysiology of some degenerative and chronic diseases

\section{Conclusion}

The present study showed significant age related histological changes of pineal gland in the form of increasing calcification and changing lobe pattern from incomplete to complete as age advances. Presence of melanin could not be demonstrated. Pathophysiological significance of this observation may be correlated with its secretory activity namely estimation of melatonin and immunohistochemical analysis of enzymes in the pinealocytes.

\section{References}

[1] Russel J Reiter. The Pineal Gland. $1^{\text {st }}$ ed. Volume 1. Anatomy and Biochemistry. CRC Press Inc., 1981: 3 - 19.

[2] Anthony L Mescher. Chapter 20. Endocrine glands. Junqueira's Basic Histology: Text and Atlas. 12th ed. McGraw Hill \& Lange; 2010: 367- 370.

[3] Barbara Young, James S Lowe, Alan Stevens, John V Heath. Chapter 17-Endocrine system. Wheater's Functional Histology: A text and colour atlas. 5th ed. Elsevier, 2006: 344.

[4] Kim E Barrett, Susan M Barman, Scott Boitano, Heddwen L Brooks. Chapter 15-Electrical activity of Brain sleep wake states and circadian rhythm. Section 3. Ganong's review of Medical Physiology. 23rd ed. Tata McGraw Hill, 2010: 238, 239.
[5] Chummy S Sinnatamby. Chapter 7-Central nervous system-Part one, Forebrain. Last's anatomy Regional and applied: 11th ed. Churchill Livingstone, 2006: 48.

[6] Lopez Munoz F, Molina J D, Rubio G, Alamo C. An historical view of the pineal gland and mental disorders. J Clin Neurosci. 2011; Aug; 18 (8): 1028 - 1037

[7] Bertram G. Katzung, Susan B. Masters, Anthony J. Trevor. Chapter 64-Dietary supplements \& Herbal medications. Basic and Clinical Pharmacology. 11th ed. Tata McGraw Hill, 2009: 1123-1124.

[8] Koshy S \& Vettivel. Melanin Pigments in Human Pineal Gland. J Anat. Soc. India, 2001; 50(2): 122-126.

[9] Dezna C Sheehan, Barbara B Hrapchak. Chapter 2 - Fixation. Chapter 12 - Pigments and minerals. Chapter 14, Nerve tissue. Chapter 15- Special cells and tissues. Theory and Practice of Histotechnology. $2^{\text {nd }}$ ed. Mosby Company, 1980: 43, 47, $220-$ 222, 227,260, 277.

[10] C F A Culling, R T Allison, W T Barr. Chapter 4- Processing. Chapter 5 - Microtomy. Chapter 7 - Staining procedure. Chapter 8 - Haematoxylins and counterstains. Cellular pathology Technique. $4^{\text {th }}$ ed. Butterworths \& Co. (Publishers) Ltd, 1985: 55 - 63, 91 - 95, 135 - 139, 146, 151, 155 - 160.

[11] John D Bancroft, Alan Stevens. Chapter 3- Tissue processing. Chapter 13 - Pigments and minerals. Chapter 16 - Bone. Theory and Practice of Histological Techniques. $3^{\text {rd }}$ ed. Churchill Livingstone, 1990: 45 - 52, 253 - 255, 333.

[12] R.A.B. Drury, E.A. Wallington. Chapter 11- Bone and decalcification. Chapter 14- Pigments. Chapter 19- The nervous System. Carleton's Histological Technique. $5^{\text {th }}$ ed. Oxford University Press, 1980: 217, 269 - 271, 373.

[13] Eugenia R. A. Cooper. The human pineal gland and pineal cysts. J Anat (Lond). 67: 28-46.

[14] Svetlana Antic, Ivan Jovanovic, Natalija Stefanovic, Snezana Pavlovic, Gorana Rancic, Sladana Ugrenovic. Morphology and histochemical characteristics human pineal gland acervuli during the aging. Facta Universitatis Series. Medicine and Biology. 2004; Vol.11, No 2: 63 - 68 .

[15] Gusek. W. Histology of the pineal gland in the elderly human. Adv Gerontol. 1983; May, 13(3): 111-114.

[16] Wu YH, Swaab D F. The human pineal gland and melatonin in aging and Alzheimer's disease. J Pineal Res. 2005; Apr, 38(3): 145- 152.

[17] Savel'ev S V, Erofeev E A, Fokin E I, Gulimoa V I, De Clerq N, PostNov A A. Human epiphyseal concrements in schizophrenia. Arkh Patol. 2004; Jul-Aug, 66 (4): 13-16.

[18] Yunqian Li, Gang Zhao, Honglei Wang, Wanan Zhu, Limei Qu, Ye Li, Jinlu Yu. Use of 3D-computed tomography angiography for planning the surgical removal of pineal region meningiomas using Poppen's approach. World Journal of Surgical Oncology. 2011; 9: 64 . 